\title{
Effect of monosodium glutamate on striato-hippocampal acetylcholinesterase level in the brain of male Wistar albino rats and its implications on learning and memory during aging
}

\author{
P. G. Sreejesh and E. Sreekumaran*
}

Department of Life Sciences, University of Calicut, Malappuram district, Kerala, India, 673635

\begin{abstract}
Glutamate is one of the most abundant excitatory neurotransmitters of brain, plays an important role in learning and memory. Monosodium glutamate (MSG) is a sodium salt of L-glutamate, a well-known flavor enhancer. Because of its capacity to increase the palatability, nowadays it is most widely used in all households and fast foods. The present study investigates the effect of MSG on striato-hippocampal acetylcholinesterase (AChE) level in the brain of male wistar albino rats and its implications on learning and memory during aging. The experimental groups consisted of 3 - 4 weeks old Wistar albino rats and were divided into group I and group II. These groups were again subdivided into control group treated with laboratory diet, $100 \mathrm{mg}$ MSG, $400 \mathrm{mg}$ MSG, $2 \mathrm{~g}$ MSG and 4 g MSG group treated with various doses of MSG/ kg body weight for sixty days. Immediately after 60 days of MSG treatment, the group I was used for the analysis of body weight, T-maze test, novel object recognition test (NOR) and AChE level while group II was kept free of MSG for further sixty days and later used for the above experiments. The results showed that group I animals neither have a dose dependent increase in body weight, a decline in the T-maze response, reduced discrimination index in NOR test and an increase in AChE level. However, the changes were significant at $4 \mathrm{~g}$ MSG treated group. The group II animals did not showed any significant differences when compared to control group. Thus the study revealed that a long term administration of MSG has a capacity to cause cognitive impairment but is not perpetual, during the life time, due to normal diet and natural healing mechanisms in the body ameliorates the toxic effects of MSG and showed gradual increase in the cognitive parameters, however it take a long time.
\end{abstract}

KEY WORDS: MSG, T-MAZE, NOVEL OBJECT RECOGNITION TEST, ACETYLCHOLINE ESTERASE

\section{ARTICLE INFORMATION:}

*Corresponding Author: drsreekumaran@uoc.ac.in Received $21^{\text {th }} \mathrm{Feb}, 2018$

Accepted after revision $27^{\text {th }}$ March, 2018

BBRC Print ISSN: 0974-6455

Online ISSN: 2321-4007 CODEN: USA BBRCBA

- Thomson Reuters ISI ESC / Clarivate Analytics USA and

Crossref Indexed Journal

NAAS Journal Score 2017: 4.38 SJIF 2017: 4.196

- A Society of Science and Nature Publication, Bhopal India 2018. All rights reserved.

Online Contents Available at: http//www.bbrc.in/

DOI: $10.21786 / \mathrm{bbrc} / 11.1 / 11$ 


\section{INTRODUCTION}

Monosodium glutamate is a sodium salt of L-glutamate, a well known flavor enhancer and a source for the unique flavor called "umami". Free glutamic acid produces Umami or pleasant savoury taste, one of the five primary tastes. The presence of MSG in food increases the palatability or alters and magnifies the desirable taste, thus it is an essential part of human diet and commonly found in most of the Asian Western diets. Body can never discriminate the glutamate coming from the monosodium glutamate and natural foods. The glutamate released from food or from the MSG is absorbed into the enterocytes from the lumen. Glutamate is an important oxidative substance for intestinal mucosa and additionally is a precursor for arginine, proline and glutathione. Glutamate is one of the most abundant excitatory neurotransmitter in brain acting through NMDA (N-methyl-D-aspartate) and AMPA ( $\alpha$-amino-3hydroxy-5-methyl-4-isoxazolepropionic acid) receptors and play a pivot role in learning and memory (Riedel et al., 2003; Jinap \&t Hajeb, 2010; Moneim et al., 2018).

The Food and Drug Administration (FDA) reported that an unknown percentage of the population might react to MSG and develop symptoms that constitutes a syndrome including burning sensation at the back of the neck, forearms, chest, headache, chest pain, facial pressure/tightness, nausea, palpitation, numbness at the back of the neck, radiating to the arms and back, tingling, warmth, weakness in face, temples, upper back, neck and arms, drowsiness and weakness collectively called MSG symptom complex (FDA, 1995). Animal studies also show that increased administration of MSG increased blood glutamate level (Bogdanov et al., 1996). Neonatal administration leads to immature blood brain barrier (Boonnate et al., 2015), degenerative changes in hypothalamic arcuate nucleus (Holzwarth-Mcbride et al., 1976), reduced serotonin and cognitive functioning (Moneim et al., 2018), pyknotic Purkinje and granule cells with inflamed cells in the cerebellum (Hashem et al., 2012). Another study showed that $4 \mathrm{~g}$ MSG treated group had an increase in the body weight, but mild doses did not show any increase in the body weight (Sari et al., 2018).

The present study investigates the effect of monosodium glutamate on striato-hippocampal acetylcholinesterase level in the brain of male wistar albino rats and its implications on learning and memory during aging.

\section{MATERIALS AND METHODS}

Male Wistar albino rats, about $30-50 \mathrm{~g}$ weight and approximately $3-4$ week rats were used for the study. The rats were maintained under laboratory conditions in the animal house of the Department of Life Sciences (Reg\#426/2/CPCSEA). All experiments were carried out according to the guidelines of the Committee for the Purpose of Control and Supervision on Experiments on Animals (CPCSEA), India and approved by the Institutional Animal Ethics Committee (IAEC) of the University of Calicut, Kerala.

The rats were divided into two groups namely group I and group II, which is again subdivided in to Control: treated with normal laboratory diet, $100 \mathrm{mg}$ MSG group: treated with $100 \mathrm{mg}$ MSG/ kg body weight, $400 \mathrm{mg}$ MSG group: treated with $400 \mathrm{mg}$ MSG/ kg body weight, $2 \mathrm{~g}$ MSG group: treated with $2 \mathrm{~g}$ MSG/ kg body weight and $4 \mathrm{~g}$ MSG group: treated with $4 \mathrm{~g}$ MSG/ kg body weight. MSG was dissolved in water and given by oral gavage for 60 days. The weights of the rats were observed during the treatment period. Immediately after sixty day of MSG administration group I rats were used for T-maze test, novel object recognition test (NOR) test and the estimation acetylcholinesterase (AChE). Group II rats were allowed to have normal diet without MSG for further 60 more days and later was used for the above experiments. The experimental design is summarised below:

T-maze test: The T-maze test was used for assessing spatial working memory in rodents, especially for

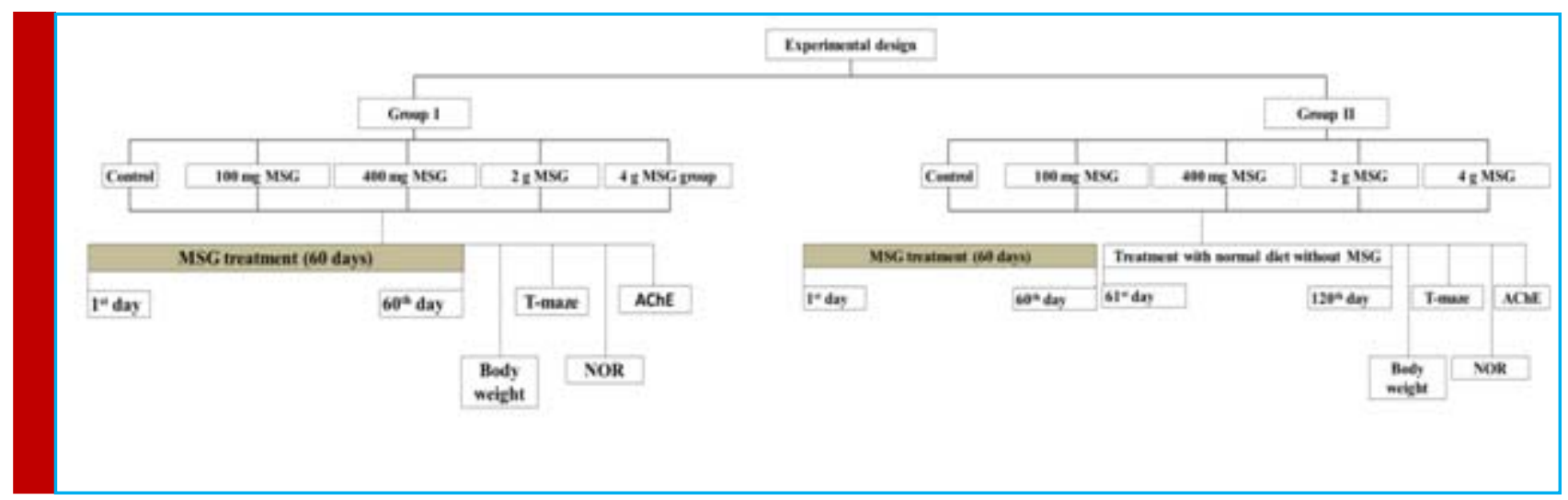




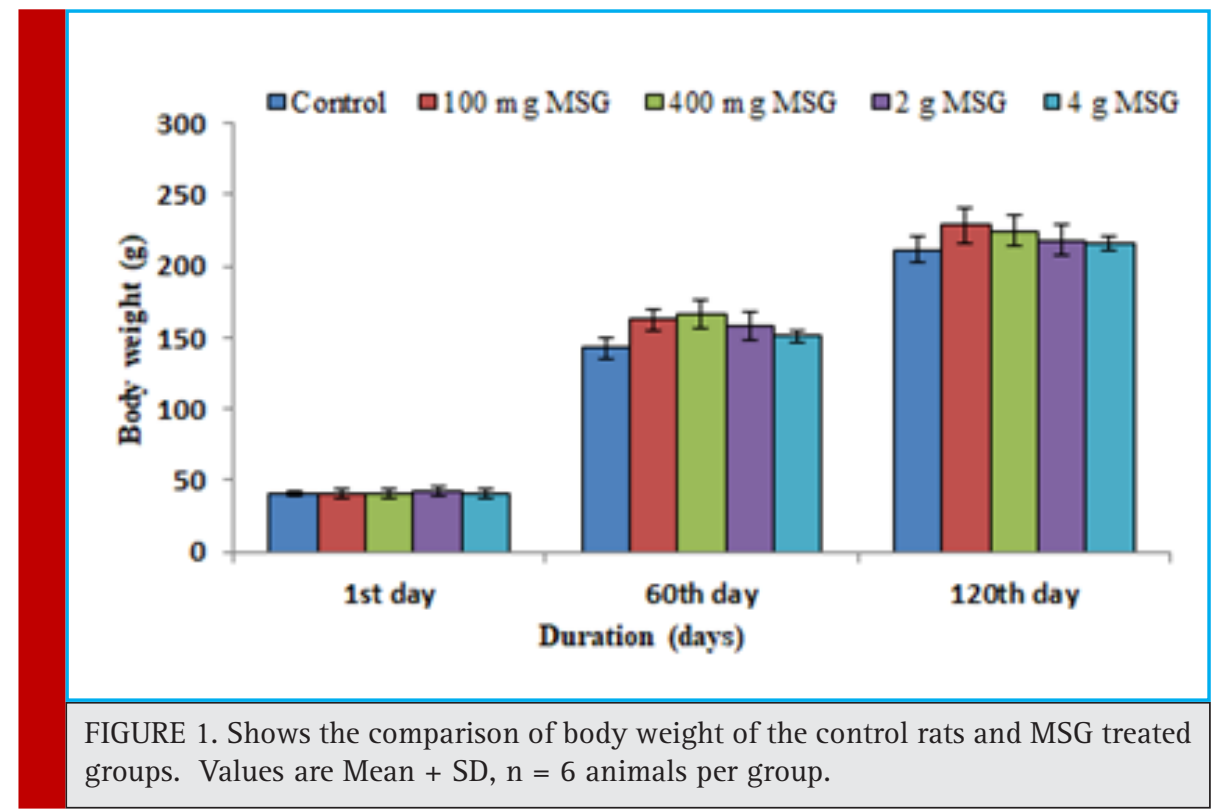

delayed alternation tasks. T-maze apparatus consists of a $\mathrm{T}$ shaped hollow wooden box with $60 \mathrm{X} 10 \mathrm{~cm}$ long tail, 50 X $10 \mathrm{~cm}$ short arms and $40 \mathrm{~cm}$ high walls. The experimental rat was exposed to the T-maze 2 days before the test for habituation. On the experiment day, after acclimatization, rats were place at the starting end of the long tail of the T-maze and allowed to explore the apparatus. In one of the short arm of the T-maze, animal feed was placed in such a way that the rat is not able to see it, as soon as it reaches the end of the long arm. When the animal reaches the food, that move was taken as a positive response. When it moves to the other end, that move was taken as a negative response. Ten trials were given for a set with a gap of 5 minutes per set. The trials were continued till a set gets at least $90 \%$ positive response. Then the total number of positive responses was added in all the sets and divided by the total number of trials given in all the sets to get the percentage of positive response (Deacon, 2013).

Novel object recognition test (NOR): NOR test is a nonforce driving and spontaneous test for recognition memory, introduced by Ennanceur and Delacour in 1988. The apparatus consists of a wooden box of size 60 X 50 X 45 $\mathrm{cm}$ with different shaped objects. NOR test has 3 phases including a habituation phase, a training phase and a test phase in each rat. During the habituation phase, the rat was placed in the NOR apparatus and allowed to adapt for 30 min without any objects. The next day, during the training phase, two identical objects were presented to the rat and allowed to explore the objects for 10 minutes. Twenty-four hours after the training phase, during the test phase, one of the old objects was replaced with a novel object and presented to each rat and allowed to explore the objects for 6 minutes. The object exploration time was recorded and find out discrimination between two objects (familiar and novel) by using a discrimination index (DI). DI $=$ novel object exploration time/ total exploration time of both objects) - (familial object exploration time/ total exploration time of both objects) $\times 100$ (Ennaceur \& Delacour, 1988; Win-Shwe \&t Fujimaki, 2012).

Estimation of Acetylcholinesterase (AChE): AChE activity was determined by the method of Ellman et $a l ., 1961$. The enzyme acetylcholinesterase catalyses the hydrolysis of acetylcholine into thiocholine and acetic acid. Thiocholine reacts with DTNB (5, 5'-dithiobis (2-nitrobenzoic acid) to form yellow coloured anions of 5-thio-2- nitrobenzoic acids, which is measured spectrophotometrically at $412 \mathrm{~nm}$. The enzyme activity was expressed as nano moles of conjugate formed/ Min/ mg of protein with the molar extinction coefficient $2.52 \mathrm{X}$ $10^{4} \mathrm{M}^{-1} \mathrm{~cm}^{-1}$ (Srikumar et al., 2004).

Statistical analysis: Statistical analysis of the data was carried out by applying the analysis of variance (ANOVA), followed by Tukey's test with the help of SPSS software, version 21. The values were considered statistically significant when $\mathrm{p}<0.05$.

\section{RESULTS AND DISCUSSION}

Monosodium glutamate, the most widely and extensively used food additive and the source of fifth taste Umami. Because of its palatability and taste enhancing capacity, kids are more addictive to foods such as chips, soups, meats, canned foods, which are marinated by MSG. In the present study, Figure 1 shows the body weight of the group I and group II rats treated with different doses 


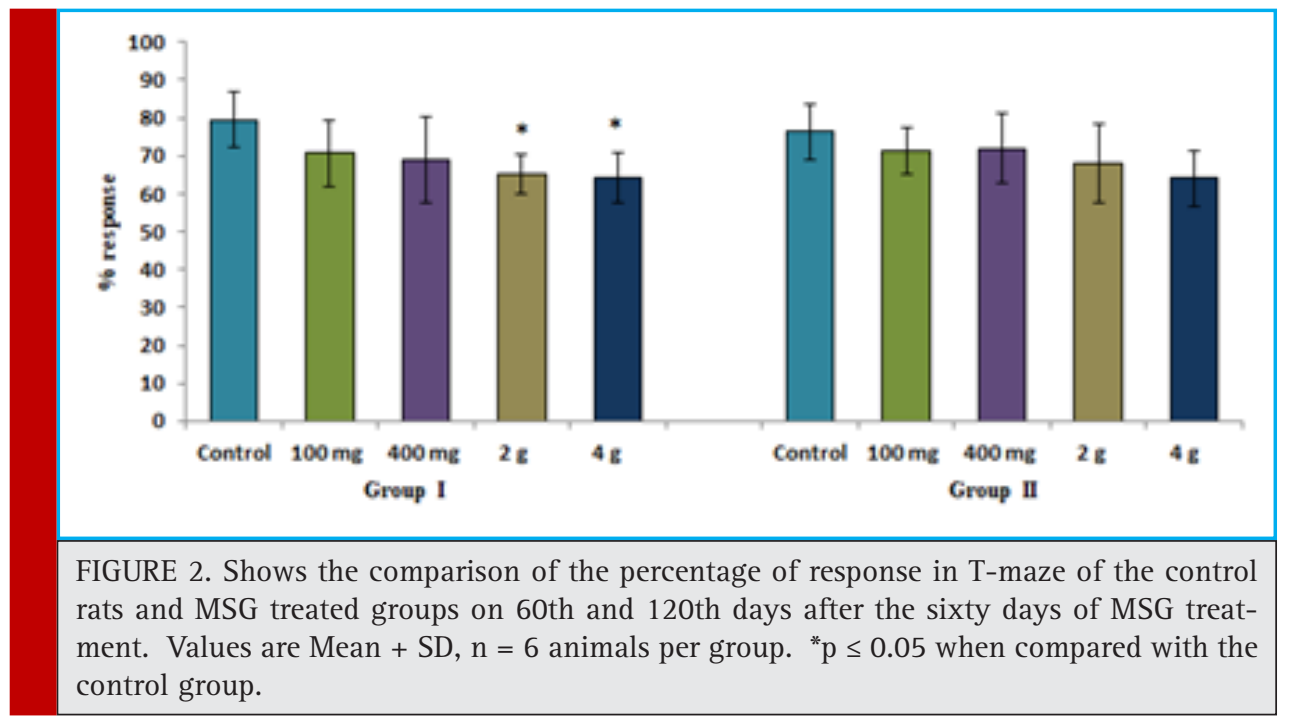

of MSG/ kg body weight. It showed that both group I and group II have a non-significant increase in the body weight.

Figure 2 shows the percentage response in the T-maze of the group I and group II rats treated with different doses of MSG/ kg body weight. Immediately after the MSG treatment, the group I rats displayed a dose dependent decline in the percentage response in T-maze while $2 \mathrm{~g}$ and $4 \mathrm{~g}$ MSG treated groups showed a significant decline when compared to the control group. The group II rats, which had no MSG exposure during the last 60 days also showed a decline in the T-maze response while it has no significant difference when compared to the control group.

Figure 3 shows the DI during thirty minute exploration of NOR apparatus of group I and group II rats treated with different doses of MSG/ kg body weight.
In group I rats, the subgroups treated with various doses of MSG showed a dose dependent decline in the DI of NOR test while the high dose, $4 \mathrm{~g}$ MSG treated subgroup showed a significant $(p \leq 0.05)$ decline when compared to the control group. The group II rats did not show any significant difference when compared with the control group even though there is a visible decline.

Figure 4: shows the enzyme AChE level in the striatum and hippocampal region of the brain in Group I and group II rats treated with different doses of MSG/ $\mathrm{kg}$ body weight. The group I rats showed a non-significant elevation in the enzyme AChE level in the striatum and hippocampal region of the brain. However, the subgroup treated with $4 \mathrm{~g}$ MSG/ kg body weight showed a significant increase $(p \leq 0.05)$ in the enzyme AChE in hippocampal region of the brain when compared to the

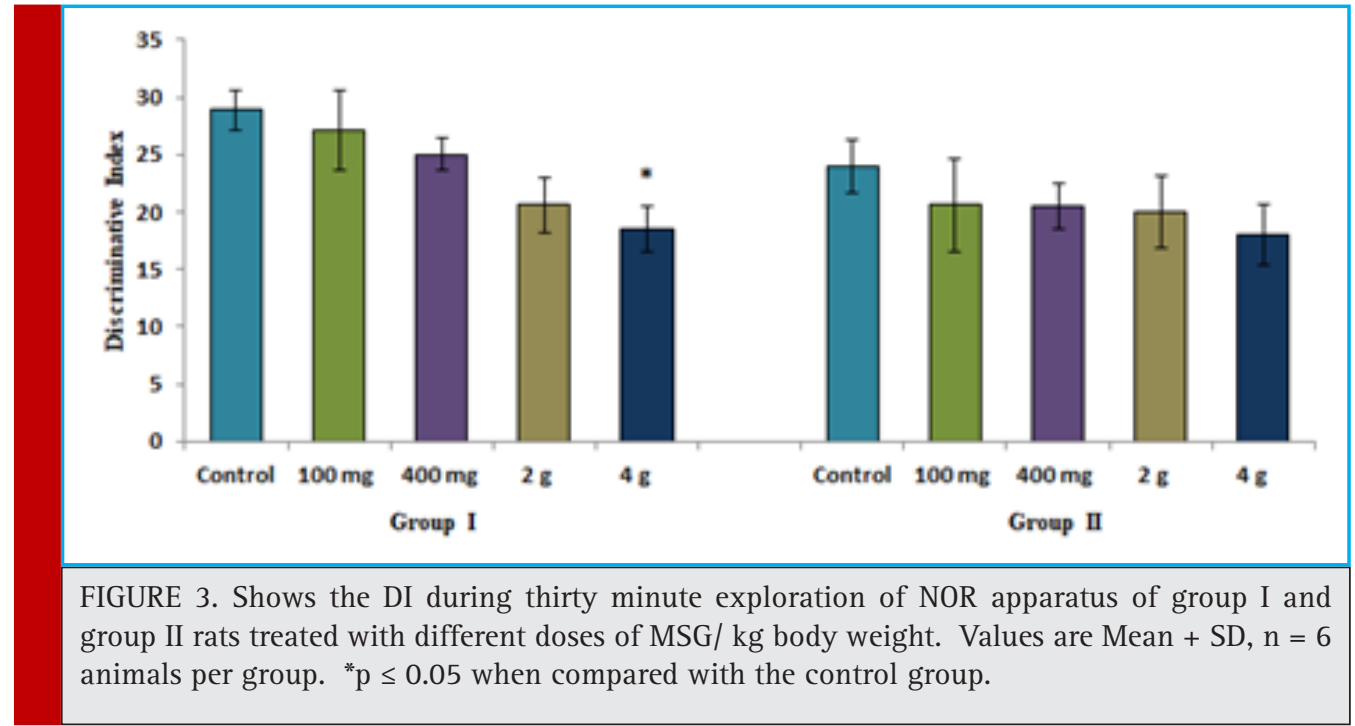




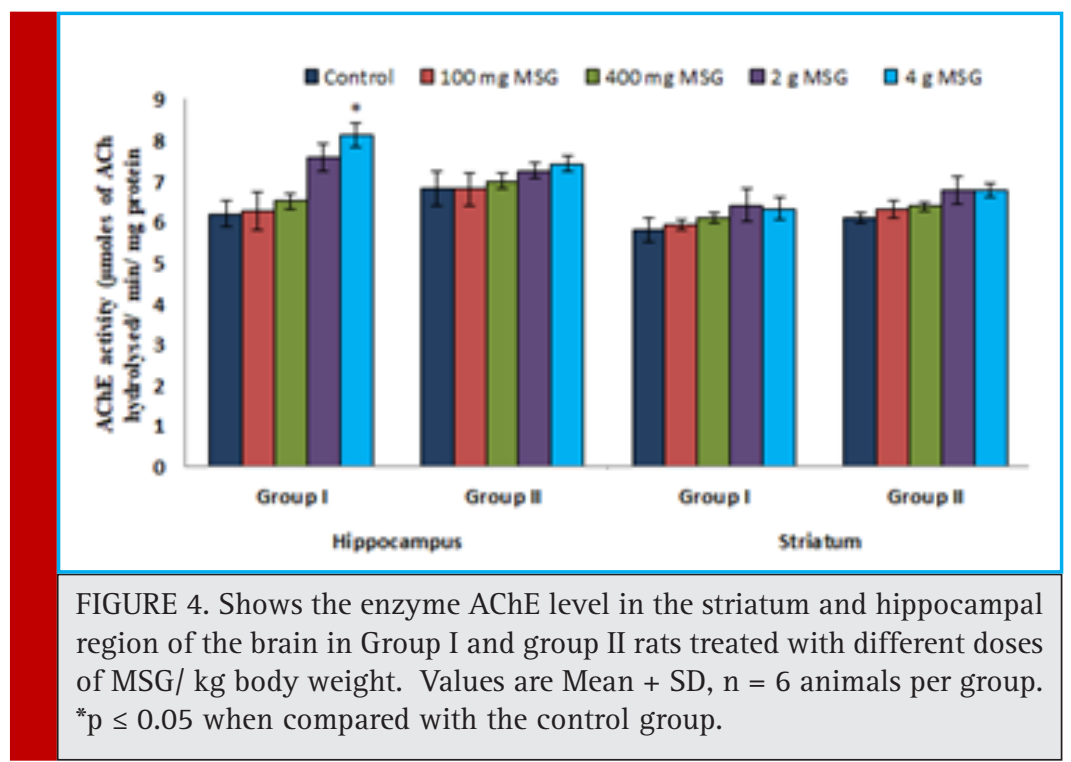

control group. The group II rats did not show any significant difference in the AChE level in straitum and hippocampal region of the brain when compared to the control group.

These results are also validated by earlier studies, which shows that MSG has the capacity to induce obesity associated with an increase in Lee index, fat accumulation, dyslipidemia and insulin resistance (Lobato et al., 2011; Alarcon-Aguilar et al., 2007). MSG increases insulin resistance and thereby increases blood insulin level, blood glucose plasma levels and also an increase in the plasma total cholesterol, triglycerides, low-density lipoprotein cholesterol (LDL-C), high-density lipoprotein cholesterol (HDL-C) and free fatty acid levels. It also reduces the cortisol induced lipolysis (Zhang et al., 2010).

Monosodium glutamate induced obese rats displayed adipose tissue hypertrophy, elevated levels of insulin, leptin and slightly elevated serum glucose. The condition which causes increased blood sugar level and insulin level is called as insulin resistance, may be it is because of the activation of phosphotyrosine protein dephosphorylation and reduced level of protein tyrosine phosphorylation, which reduces the development of Gai2 G-protein, i.e., essential for the activation of insulin signaling to GLUT4 and transportation of glucose (Baculikova et al., 2008). A clinical study in humans from Thailand revealed that MSG consumption is associated with the risk of having metabolic syndrome and being overweight (Pepino et al., 2010). Another study evidenced that an intravenous administration of MSG produces obesity, increased blood glucose, insulin, total cholesterol, and triglyceride levels (Nagata et al., 2006), but it did not show any polyphagia which may be due to the excessive stimulation of the vagus nerve (Balbo et a., 2000). Neonatal administration of MSG produces hypothalamus induced obesity (Braga et al., 2001). Another study showed that $4 \mathrm{~g}$ MSG treated group has an increase in the body weight, but mild doses did not show any increase in the body weight (Sari et al., 2018).

The percentage response in the T-maze and DI of NOR obtained from the group I explains the poor cognitive functioning. The increased level of AChE may break the neurotransmitter acetylcholine, which act through NMDA and AMPA receptors to assist in cognition. But after administration of MSG, in group II the toxic effects are gradually reducing and it is slightly fast in low dose treated subgroups and very slow in high dose treated subgroups. A study showed that the neonatal treatment of MSG induces obesity, elevated insulin secretion and acetylcholinesterase level. MSG also increases the activation of parasympathetic tone, which cause hyper secretion of insulin from the pancreas (Balbo et al., 2000). Measurement of neurotransmitters and neurotransmitter related enzymes in hypothalamic nuclei from MSGtreated rats revealed normal levels of norepinephrine, serotonin and glutamic acid decarboxylase, but reduced levels of choline acetyltransferase, dopamine and an elevated level of acetylcholinesterase in hypothamic nuclei. It is confirmed that MSG-induced endocrine deficiency syndrome results in the destruction of cholinergic and dopaminergic tuberoinfundibular systems in the hypothalamus (Nemeroff et al., 1978). Another study showed that subchronic MSG dose was anxiogenic and showed a slightly retardant effect on spatial working memory (Onaolapo et al., 2012). Postnatal treatment of MSG in mice showed that there is a decrease in choline acetyl- 
transferase and a huge increase in AChE activity (Ross et al., 1975). Hassan et al., (2014) showed that MSG consumption may have immunotoxic effects on the thymus and spleen of adult rats, which is reversible though the normal structure of the spleen would need time to be regained (Hassan et al., 2014).

\section{CONCLUSION}

Monosodium glutamate is a salt of L-glutamate, which is an abundant neurotransmitter and essential for cognitive functioning but high doses is shown to have neurotoxic. Low dose of MSG treatment doesn't cause any much decline in cognition but it increases body weight. However, high dose of MSG administration increases the body weight and significantly reduce the cognitive functioning due to the decline in acetylcholine and elevation of acetylcholine esterase. But during the life time, due to normal diet and natural healing mechanisms in the body ameliorates the toxic effects of MSG and showed gradual increase in the cognitive parameters. More detailed studies are also needed to reveal the exact mechanism behind the fluctuation of cognition.

\section{ACKNOWLEDGMENT}

Authors are thankful to the department of Life Sciences, University of Calicut for the funding and support.

\section{CONFLICTS OF INTEREST}

Nil

\section{REFERENCES}

Alarcon-Aguilar, F. J., Zamilpa, A., Perez-Garcia, M. D., Almanza-Perez, J. C., Romero-Nunez, E., Campos-Sepulveda, E. A., Roman-Ramos, R. (2007). Effect of Hibiscus sabdariffa on obesity in MSG mice. Journal of Ethnopharmacology, 114(1), 66-71.

Baculikova, M., Fiala, R., Jezova, D., Macho, L., \&t Zorad, S. (2008). Rats with monosodium glutamate-induced obesity and insulin resistance exhibit low expression of Galpha (i2) G-protein. Gen Physiol Biophys, 27, 222-226.

Balbo, S. L., Gravena, C., Bonfleur, M. L., \&t de Freitas Mathias, P. C. (2000). Insulin secretion and acetylcholinesterase activity in monosodium l-glutamate-induced obese mice. Hormone Research in Paediatrics, 54(4), 186-191.

Bogdanov, M. B., Tjurmina, 0. A., \&t Wurtman, R. J. (1996). Consumption of a high dietary dose of monosodium glutamate fails to affect extracellular glutamate levels in the hypothalamic arcuate nucleus of adult rats. Brain Research, 736(1-2), 76-81.

Boonnate, P., Waraasawapati, S., Hipkaeo, W., Pethlert, S., Sharma, A., Selmi, C., ... Cha'on, U. (2015). Monosodium gluta- mate dietary consumption decreases pancreatic $\beta$-cell mass in adult Wistar rats. PloS One, 10(6), e0131595.

Braga, L. R., Ribeiro, I. A., \&t Gobatto, C. A. (2001). Glucose tolerance and insulin action in monosodium glutamate (MSG) obese exercise-trained rats. Physiological Chemistry and Physics and Medical NMR, 33(1), 63-71.

Deacon, R. M. J. (2013). Measuring the strength of mice. Journal of Visualized Experiments: JoVE, (76).

Ennaceur, A., \&t Delacour, J. (1988). A new one-trial test for neurobiological studies of memory in rats. 1: Behavioral data. Behavioural Brain Research, 31(1), 47-59.

FDA and Monosodium Glutamate (MSG), U. S. Department of Health and Human Services, U. S. Food and Drug Administration. (1995). U. S. Department of Health and Human Services, U. S. Food and Drug Administration.

Hashem, H. E., Safwat, M. D. E.-D., \&t Algaidi, S. (2012). The effect of monosodium glutamate on the cerebellar cortex of male albino rats and the protective role of vitamin C (histological and immunohistochemical study). Journal of Molecular Histology, 43(2), 179-186.

Hassan, Z. A., Arafa, M. H., Soliman, W. I., Atteia, H. H., \& Al-Saeed, H. F. (2014). The effects of monosodium glutamate on thymic and splenic immune functions and role of recovery (biochemical and histological study). Journal of Cytology \& Histology, 5(6), 1.

Holzwarth-Mcbride, M. A., Sladek, J. R., \&t Knigge, K. M. (1976). Monosodium glutamate induced lesions of the arcuate nucleus. II. Fluorescence histochemistry of catecholamines. The Anatomical Record, 186(2), 197-205.

Jinap, S., \& Hajeb, P. (2010). Glutamate. Its applications in food and contribution to health. Appetite, 55(1), 1-10.

Lobato, N. S., Filgueira, F. P., Akamine, E. H., Davel, A. P. C., Rossoni, L. V, Tostes, R. C., ... Fortes, Z. B. (2011). Obesity induced by neonatal treatment with monosodium glutamate impairs microvascular reactivity in adult rats: role of NO and prostanoids. Nutrition, Metabolism and Cardiovascular Diseases, 21(10), 808-816.

Moneim, W. M. A., Yassa, H. A., Makboul, R. A., \&t Mohamed, N. A. (2018). Monosodium glutamate affects cognitive functions in male albino rats. Egyptian Journal of Forensic Sciences, 8(1), 9.

Nagata, m., Suzuki, w., Iizuka, s., Tabuchi, m., Maruyama, h., Takeda, s., ... Miyamoto, K. (2006). Type 2 diabetes mellitus in obese mouse model induced by monosodium glutamate. Experimental Animals, 55(2), 109-115.

Nemeroff, C. B., Lipton, M. A., \&t Kizer, J. S. (1978). Models of neuroendocrine regulation: use of monosodium glutamate as an investigational tool. Developmental Neuroscience, 1(2), 102-109.

Onaolapo, O. J., Onaolapo, A. Y., Mosaku, T. J., Akanji, 0. 0., Et Abiodun, 0. R. (2012). Elevated plus maze and Y-maze behavioral effects of subchronic, oral low dose monosodium glutamate in Swiss albino mice. J Pharm Biol Sci, 3(4), 2127. 
Pepino, M. Y., Finkbeiner, S., Beauchamp, G. K., \&t Mennella, J. A. (2010). Obese women have lower monosodium glutamate taste sensitivity and prefer higher concentrations than do normal-weight women. Obesity, 18(5), 959-965.

Riedel, G., Platt, B., \&t Micheau, J. (2003). Glutamate receptor function in learning and memory. Behavioural Brain Research, 140(1-2), 1-47.

Ross, D., Cohen, A. I., \&t McDougal, D. B. (1975). Choline acetyltransferase and acetylcholine esterase activities in normal and biologically fractionated mouse retinas. Investigative Ophthalmology \&t Visual Science, 14(10), 756-761.

Sari, M. I., Rahmat, N. B., \&t Wijaya, D. W. (2018). Effect of Prunus dulcis Extract against Total Cholesterol Level in Mice that Given Monosodium Glutamate. In IOP Conference Series:
Materials Science and Engineering (Vol. 288, p. 12097). IOP Publishing:

Srikumar, B. N., Ramkumar, K., Raju, T. R., \&t Shankaranarayana, R. B. S. (2004). Assay of acetylcholinesterase activity in the brain. Brain and Behavior, 142-144.

Win-Shwe, T., \&t Fujimaki, H. (2012). Acute administration of toluene affects memory retention in novel object recognition test and memory function-related gene expression in mice. Journal of Applied Toxicology, 32(4), 300-304.

Zhang, N., Huan, Y., Huang, H., Song, G., Sun, S., \&t Shen, Z. (2010). Atorvastatin improves insulin sensitivity in mice with obesity induced by monosodium glutamate. Acta Pharmacologica Sinica, 31(1), 35. 